\title{
Sympathetic Nerve Discharge Is Coupled to Muscle Cell pH during Exercise in Humans
}

\author{
Ronald G. Victor, Loren A. Bertocci, Susan L. Pryor, and Ray L. Nunnally \\ Departments of Internal Medicine (Cardiology Division) and Radiology, Harry S. Moss Heart Center, and the Biomedical \\ Nuclear Magnetic Resonance Center, University of Texas Southwestern Medical Center, Dallas, Texas 75235
}

\begin{abstract}
We used phosphorus nuclear magnetic resonance spectroscopy ( $\left.{ }^{31} \mathrm{P}-\mathrm{NMR}\right)$ to probe the cellular events in contracting muscle that initiate the reflex stimulation of sympathetic outflow during exercise. In conscious humans, we performed ${ }^{31} \mathrm{P}-\mathrm{NMR}$ on exercising forearm muscle and simultaneously recorded muscle sympathetic nerve activity (MSNA) with microelectrodes in the peroneal nerve to determine if the activation of MSNA is coupled to muscle $\mathrm{pH}$, an index of glycolysis, or to the concentrations (II) of inorganic phosphate $\left(P_{i}\right)$ and adenosine diphosphate (ADP) which are modulators of mitochondrial respiration. During both static and rhythmic handgrip, the onset of sympathetic activation in resting muscle coincided with the development of cellular acidification in active muscle. Furthermore, increases in MSNA were correlated closely with decreases in intracellular pH but dissociated from changes in phosphocreatine ([PCr]), $\left[\mathbf{P}_{\mathrm{i}}\right]$, and [ADP]. The principal new conclusion is that activation of muscle sympathetic outflow during exercise in humans is coupled to the cellular accumulation of protons in contracting muscle.
\end{abstract}

\section{Introduction}

Although many of the cardiovascular adjustments during exercise are mediated by the sympathetic nervous system, the precise mechanisms that regulate sympathetic outflow during exercise are still unknown. Two principal theories have been proposed. The first is that the central command signal from the rostral brain that initiates voluntary muscle contraction also projects to autonomic circuits in the brainstem to cause parallel activation of motor and sympathetic neurons (1). The second theory is that sympathetic excitation is triggered by a somatic reflex arising in the contracting skeletal muscle $(2,3)$. Although there is experimental support for both theories, this report focuses only on the reflex mechanism because recent technological advances have improved our ability to test this theory in conscious humans.

There is increasing evidence that the reflex stimulation of sympathetic outflow by muscle contraction is mediated in part

A preliminary report of this work was presented at the Annual Scientific Sessions of the American Heart Association (Victor, R. G., et al. 1987. Circulation. 76:IV-61).

Address reprint requests to Dr. Victor, Cardiology Division, UT Southwestern Medical Center, 5323 Harry Hines Blvd., Dallas, Texas 75235-9034. 1988.

Received for publication 7 March 1988 and in revised form 7 June

J. Clin. Invest.

(C) The American Society for Clinical Investigation, Inc. $0021-9738 / 88 / 10 / 1301 / 05 \$ 2.00$

Volume 82, October 1988, 1301-1305 by local metabolites acting on thin fiber muscle afferent nerve endings $(4,5)$. Although the discharge of these chemosensitive afferents is thought to signal the brain of a mismatch between muscle blood flow and metabolism (6), little is known about the specific metabolic events that are involved.

Oxidative phosphorylation and glycolysis are the primary pathways for the production of high-energy phosphates in mammalian skeletal muscle. The goal of this study, therefore, was to determine whether the stimulation of sympathetic outflow during exercise is coupled either to the production of inorganic phosphate $\left(\mathrm{P}_{\mathrm{i}}\right)^{1}$ and $\mathrm{ADP}$, which are regulators of mitochondrial respiration in working muscle, or to muscle cell $\mathrm{pH}$, an index of glycolysis. To test these possibilities, we monitored cellular high energy phosphates and $\mathrm{pH}$ in exercising forearm muscle with ${ }^{31} \mathrm{P}$ nuclear magnetic resonance (NMR) spectroscopy and simultaneously recorded sympathetic nerve discharge to resting leg muscle with intraneural microelectrodes in conscious humans.

\section{Methods}

11 healthy volunteers (eight men and three women), aged 24-37 yr, participated in this study after providing informed written consent. The experimental protocol was approved by the Institutional Review Board for human investigation. All subjects were normotensive (arterial pressure $<140 / 90 \mathrm{mmHg}$ ), were taking no medications, and had no evidence of cardiopulmonary diseases on history or physical examination.

Subjects were studied in the supine position with the left arm placed in a $30-\mathrm{cm}$ horizontal bore 1.9 Tesla superconducting magnet (Oxford Instruments, Oxford, UK) interfaced to a NT-80 console (formerly Nicolet Magnetics Corp., now GE/NMR, Fremont, CA). A 3.5cm surface coil, tuned to the ${ }^{31} \mathrm{P}$ resonance frequency of $32.54 \mathrm{MHz}$, was placed over the region of the flexor digitorum profundus muscle. Magnetic resonance spectra were acquired in 60-s intervals and represented the time average of 24 acquisitions. The radiofrequency pulse width $(30 \mu \mathrm{s})$ was adjusted empirically to provide the optimum signalto-noise ratio. Peak heights and areas were calculated to estimate relative changes in the cellular concentrations of phosphocreatine [PCr], inorganic phosphate $\left[\mathrm{P}_{\mathrm{i}}\right]$, and adenosine triphosphate $[\mathrm{ATP}]$. The chemical shift $(\delta)$ of $\mathrm{P}_{\mathrm{i}}$ relative to $\mathrm{PCr}$ was used to estimate intracellular $\mathrm{pH}(7)$ according to the following equation (8): $\mathrm{pH}=6.75+\log (\delta$ $-3.27) /(5.69-\delta)$.

The creatine kinase equilibrium reaction (9) was used to calculate the free intracellular [ADP]: $[\mathrm{ADP}]=([\mathrm{Cr}][\mathrm{ATP}]) /\left([\mathrm{PCr}]\left[\mathrm{P}_{\mathrm{i}}\right] \mathrm{keq}\right)$, with $\mathrm{keq}=1.66 \times 10^{9} \mathrm{~kg} / \mathrm{mol}$. A value of $5.5 \mathrm{mmol} / \mathrm{kg}$ was assumed for [ATP] and of $32 \mathrm{mmol} / \mathrm{kg}$ for [PCr] $+[\mathrm{Cr}](9)$.

Both ADP (10) and $P_{i}(11)$ have been implicated as regulators of mitochondrial respiration; $[\mathrm{PCr}] /\left[\mathrm{P}_{\mathrm{i}}\right]$ has been proposed as an index of mitochondrial respiration state (12). $\mathrm{pH}$ was used as an index of glycolysis.

1. Abbreviations used in this paper: MSNA, muscle sympathetic nerve activity; MVC, maximal voluntary contraction; NMR, nuclear magnetic resonance; $\mathrm{PCr}$, phosphocreatine; $\mathrm{P}_{\mathrm{i}}$, inorganic phosphate. 
Multiunit recordings of postganglionic sympathetic nerve activity were obtained with unipolar tungsten microelectrodes inserted into muscle nerve fascicles of the right peroneal nerve posterior to the fibular head by microneurography (13). The neural signals were amplified, filtered (bandwidth of 700-2,000 Hz), rectified, and integrated to obtain a mean voltage display of muscle sympathetic nerve activity (MSNA). A recording of MSNA was considered acceptable when the neurograms revealed spontaneous, pulse-synchronous bursts that increased during the Valsalva maneuver, but not during arousal stimuli (loud noise, skin pinch). Sympathetic bursts were identified by inspection of the filtered and mean voltage neurograms. The NMR radiofrequency pulses produced spike artifacts on the neurograms at a rate of one every $2.5 \mathrm{~s}$; the neural recordings were transcribed from FM tape to hardcopy at a rapid paper speed so that these artifacts could be excluded from the analysis of nerve traffic. The neurograms and NMR spectra were analyzed independently.

In seven subjects, we succeeded in obtaining NMR spectra and sympathetic nerve recordings simultaneously as well as measurements of arterial pressure and heart rate (Dinamap oscillometric sphygmomanometer, Critikon Inc., Tampa, FL) during both static and rhythmic handgrip. Static exercise was performed using a handgrip dynamometer in the magnet for $2 \mathrm{~min}$ at $30 \%$ of maximal voluntary contraction (MVC). The rhythmic protocol lasted $4 \mathrm{~min}$ and was incremental: intermittent contractions $(\cong 1 \mathrm{~Hz})$ for $2 \mathrm{~min}$ at $30 \%$ MVC followed immediately by an additional $2 \mathrm{~min}$ at $50 \%$ MVC. Static and rhythmic modes of contraction were used because both would stimulate muscle oxygen demand, whereas only the static contraction should limit oxygen delivery due to a sustained mechanical hindrance to muscle blood flow. Immediately after both the static and the rhythmic exercise periods, the circulation to forearm was arrested by inflating a pneumatic cuff to suprasystolic pressure for an additional $2 \mathrm{~min}$; the goal was to trap local metabolites in the vicinity of the muscle afferents while eliminating central command.

In four additional subjects, we examined responses to $2 \mathrm{~min}$ of forearm ischemia alone without preceding exercise. The order of interventions was random.

Statistical analysis. Data are presented as mean \pm standard error. Statistical analysis was performed using repeated measures analysis of variance with the Bonferonni adjustment for multiple comparisons. A $P$ value $<0.05$ was considered statistically significant.

\section{Results}

Static handgrip at $30 \% \mathrm{MVC}$ increased [ADP], decreased $[\mathrm{PCr}] /\left[\mathrm{P}_{\mathrm{i}}\right]$ and $\mathrm{pH}$, and increased MSNA (Table I and Fig. 1).

During the first and second minutes of rhythmic handgrip (30\% MVC), [ADP] increased and $[\mathrm{PCr}] /\left[\mathrm{P}_{\mathrm{i}}\right]$ declined precipitously, but pH and MSNA were unchanged. In contrast, dur- ing the third and fourth minutes of the exercise (50\% MVC), there was little further change in $[\mathrm{PCr}] /\left[\mathrm{P}_{\mathrm{i}}\right]$ and $[\mathrm{ADP}]$ returned toward control, but MSNA increased progressively as pH decreased (Table II; Figs. 2 and 3).

Fig. 3 compares responses during static and rhythmic handgrip in the same subjects. When both modes of contraction were performed to comparable decreases in $[\mathrm{PCr}] /\left[\mathrm{P}_{\mathrm{i}}\right]$, only the static exercise decreased $\mathrm{pH}$ and increased MSNA. In contrast, when static and rhythmic handgrip were matched for comparable decreases in $\mathrm{pH}$, they produced comparable increases in MSNA, even though $[\mathrm{PCr}] /\left[\mathrm{P}_{\mathrm{i}}\right]$ decreased more with the rhythmic than with the static exercise.

During the forearm ischemia following both static and rhythmic handgrip, exercise-induced changes in [ADP], $[\mathrm{PCr}] /\left[\mathrm{P}_{\mathrm{i}}\right], \mathrm{pH}, \mathrm{MSNA}$, and arterial pressure were all maintained, but heart rate returned rapidly to control (Tables I and II).

Resting forearm ischemia alone ( $2 \mathrm{~min}$ ) had no effect on [ADP], [PCr]/[ $\left.\mathrm{P}_{\mathrm{i}}\right], \mathrm{pH}, \mathrm{MSNA}$, arterial pressure, or heart rate.

None of these interventions significantly altered [ATP].

\section{Discussion}

The data herein represent the first simultaneous determinations of cellular high-energy phosphates and $\mathrm{pH}$ in exercising human skeletal muscle with ${ }^{31} \mathrm{P}-\mathrm{NMR}$ spectroscopy and of sympathetic nerve discharge with microneurography. The principal new conclusion is that activation of sympathetic discharge to nonexercising muscle is coupled to the cellular accumulation of protons in the contracting muscle.

The present findings suggest that a specific chemical product of contraction may be important in causing the reflex stimulation of sympathetic outflow during exercise in humans. By comparing responses to static and rhythmic handgrip at the same metabolic endpoints in the same subjects, we were able to dissociate changes in $\mathrm{pH}$ from changes in $[\mathrm{PCr}] /\left[\mathrm{P}_{\mathrm{i}}\right]$ and examine their relationships to muscle sympathetic outflow. We found that exercise-induced increases in MSNA were directly proportional to decreases in forearm muscle cell $\mathrm{pH}$ but were unrelated to the decreases in $[\mathrm{PCr}] /\left[\mathrm{P}_{\mathrm{i}}\right]$ produced by these forms of exercise. The changes in pH and MSNA were closely related in time course as well as in magnitude. During both static and rhythmic handgrip, the nerve traffic did not increase at the onset of exercise but rather at the onset of intracellular acidification in the contracting muscle. 2 min of static hand-

Table I. Responses to Static Handgrip and to Post-Handgrip Forearm Ischemia

\begin{tabular}{|c|c|c|c|c|c|}
\hline & \multirow[b]{2}{*}{ Control } & \multicolumn{2}{|c|}{ Static handgrip ( $30 \%$ MVC) } & \multirow{2}{*}{$\begin{array}{l}\text { Post-handgrip } \\
\text { forearm ischemia }\end{array}$} & \multirow[b]{2}{*}{ Recovery } \\
\hline & & 1st $\min$ & 2nd min & & \\
\hline$[\mathrm{PCr}](\mathrm{mmol} / \mathrm{kg}$ wet $w t)$ & $26.3 \pm 0.12$ & $21.2 \pm 0.8^{*}$ & $18.6 \pm 0.8^{*}$ & $19.5 \pm 0.9^{*}$ & $24.2 \pm 0.7$ \\
\hline$\left[\mathrm{P}_{\mathrm{i}}\right](\mathrm{mmol} / \mathrm{kg}$ wet $w t)$ & $2.7 \pm 0.4$ & $8.9 \pm 0.8^{*}$ & $11.5 \pm 0.8^{*}$ & $9.1 \pm 1.6^{*}$ & $2.7 \pm 0.4$ \\
\hline [ADP] $(\mathrm{mmol} / \mathrm{kg}$ wet $\mathrm{wt})$ & $4.7 \pm 0.5$ & $20.0 \pm 2.6^{*}$ & $16.3 \pm 2.0^{*}$ & $10.2 \pm 1.4^{*}$ & $4.7 \pm 0.5$ \\
\hline $\mathrm{pH}$ & $7.0 \pm 0.1$ & $7.0 \pm 0.1$ & $6.7 \pm 0.1^{*}$ & $6.6 \pm 0.1^{*}$ & $7.0 \pm 0.1$ \\
\hline MSNA $(U)^{\ddagger}$ & $335 \pm 45$ & $402 \pm 66$ & $700 \pm 124^{*}$ & $694 \pm 118^{*}$ & $382 \pm 63$ \\
\hline $\operatorname{MAP}(m m H g)$ & $89 \pm 2$ & $97 \pm 3^{*}$ & $109 \pm 4^{*}$ & $104 \pm 3^{*}$ & $88 \pm 3$ \\
\hline HR (beats/min) & $63 \pm 4$ & $72 \pm 4^{*}$ & $78 \pm 4^{*}$ & $64 \pm 4$ & $65 \pm 4$ \\
\hline
\end{tabular}

Entries are mean \pm SE for seven subjects. Abbreviations: HR, heart rate; MAP, mean arterial pressure. $\quad * P<0.05$ vs. control values. $\quad ¥$ MSNA given in units (burst/min $\times$ mean burst amplitude). 

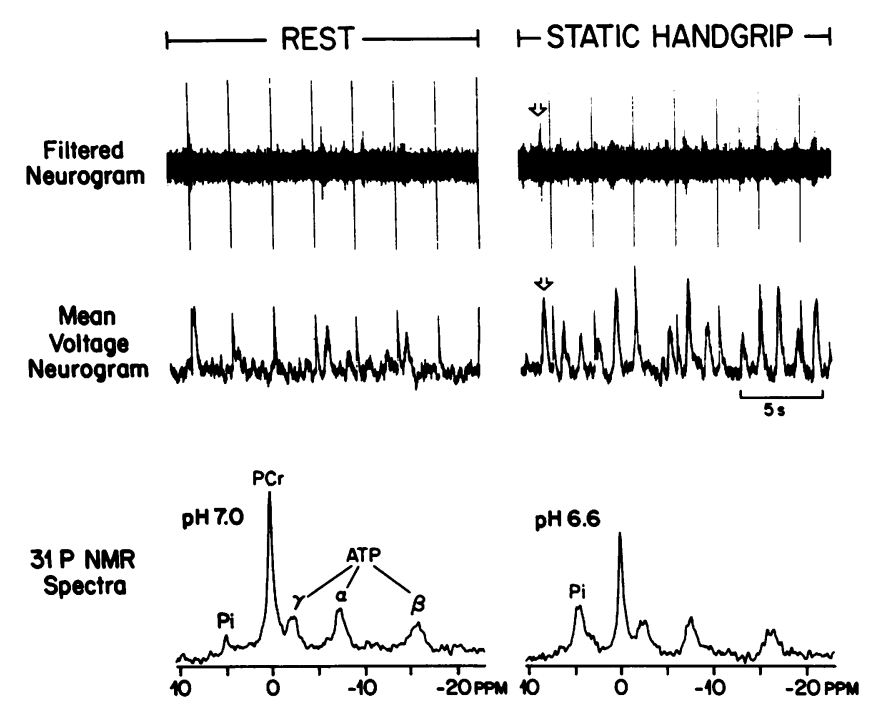

Figure 1. Illustrative ${ }^{31} \mathrm{P}-\mathrm{NMR}$ spectra and simultaneous recordings of muscle sympathetic nerve activity at rest and during static handgrip at $30 \%$ of maximum. The arrows denote a multiunit burst of sympathetic activity on both the actual and mean voltage neurograms. In contrast, the tall single spikes (one every $2.5 \mathrm{~s}$ ) are artifacts produced by NMR. On the NMR spectra, the signal intensities are proportional to $\left[\mathrm{P}_{\mathrm{i}}\right]$, [PCr], and [ATP].

grip at $30 \%$ MVC previously has been shown to increase MSNA with a latency of $\sim 60 \mathrm{~s}$ from the onset of contraction (14). The present findings indicate that this delayed pattern of sympathetic activation is related to the time required for cellular accumulation of protons in the contracting muscle.

In contrast to static handgrip, 2-min bouts of rhythmic handgrip at either $30 \%$ or $50 \%$ MVC previously have been shown to have no effect on MSNA (15); the conclusion was that brief periods of rhythmic contraction do not increase MSNA because the metabolic changes resulting from this exercise are insufficient to activate chemosensitive muscle affer-

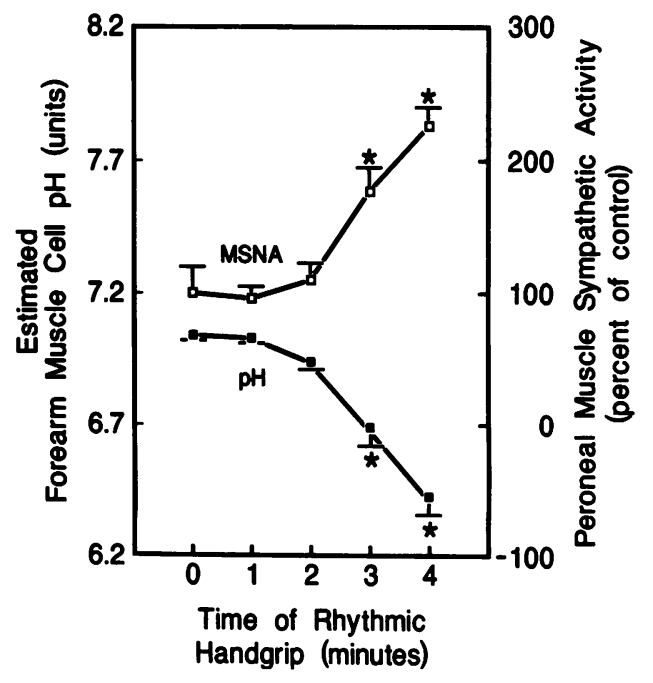

Figure 2. Responses of forearm muscle cell pH ( $₫$ ) as determined by ${ }^{3} \mathrm{P}-\mathrm{NMR}$ and of peroneal muscle sympathetic nerve activity ( $\square$ ) during $4 \mathrm{~min}$ of rhythmic handgrip ( $2 \mathrm{~min}$ at $30 \%$ MVC followed by 2 min at $50 \% \mathrm{MVC})$. Data represent mean \pm SE for seven subjects $\left({ }^{*} P\right.$ $<0.05$ vs. control).
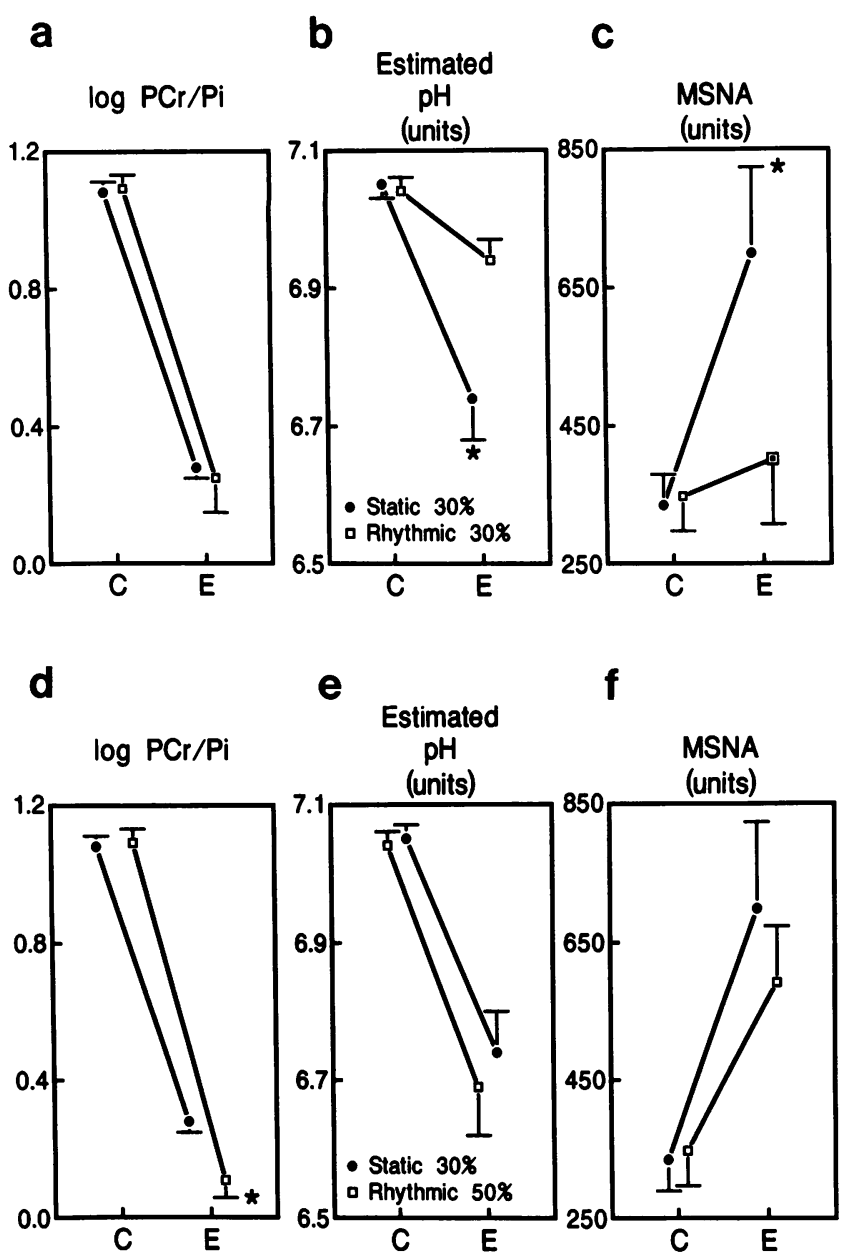

Figure 3. $(a-c)$ Responses to static and rhythmic handgrip at comparable decreases in $[\mathrm{PCr}] /\left[\mathrm{P}_{\mathrm{i}}\right]$. Values represent control $(C)$ and exercise $(E)$ for seven subjects (mean $\pm \mathrm{SE},{ }^{*} P<0.05$ static vs. rhythmic handgrip). ( $(d-f)$ Responses to static and rhythmic handgrip at comparable decreases in estimated muscle cell $\mathrm{pH}$ in the same subjects.

ents. Our findings during a 4-min protocol of incremental rhythmic handgrip ( $2 \mathrm{~min}$ at $30 \% \mathrm{MVC}$ followed immediately by an additional 2 min at 50\% MVC) provide additional support for this concept. As previously reported, MSNA did not increase during two minutes of rhythmic handgrip at $30 \%$ MVC. The important new finding is that this period of exercise did not decrease muscle cell $\mathrm{pH}$, even though $\mathrm{PCr}$ stores decreased by $33 \%$.

Another important new finding is that MSNA rose during the rhythmic handgrip at 50\% MVC. This observation might, at first glance, appear to differ importantly from previously reported findings (15). However, in the previous study, 2 min of rhythmic handgrip at $50 \%$ MVC were preceded by rest; whereas, in the present study, this level of exercise was immediately preceded by 2 min of handgrip at $30 \%$ MVC. Thus, it is not surprising that the sympathetic responses were different in the two studies because the exercise stimulus was not the same. Indeed, the incremental protocol was designed specifically to increase the preexisting rate of muscle metabolism upon which the response to rhythmic handgrip at 50\% MVC was superimposed.

In this regard, several observations indicate that the stimulation of MSNA evoked by incremental rhythmic handgrip 


\begin{tabular}{|c|c|c|c|c|c|c|c|}
\hline & \multirow[b]{3}{*}{ Control } & \multicolumn{4}{|c|}{ Rhythmic handgrip } & \multirow{3}{*}{$\begin{array}{l}\text { Post-handgrip } \\
\text { forearm ischemia }\end{array}$} & \multirow[b]{3}{*}{ Recovery } \\
\hline & & \multicolumn{2}{|c|}{ (30\% MVC) } & \multicolumn{2}{|c|}{ (50\% MVC) } & & \\
\hline & & 1 st $\min$ & 2nd min & $3 \mathrm{rd} \min$ & 4th $\min$ & & \\
\hline [PCr] $(\mathrm{mmol} / \mathrm{kg}$ wet $w t)$ & $26.3 \pm 0.2$ & $22.2 \pm 0.8^{*}$ & $17.6 \pm 1.5^{*}$ & $15.7 \pm 0.8^{*}$ & $14.2 \pm 0.6^{*}$ & $14.1 \pm 0.7^{*}$ & $26.3 \pm 1.2$ \\
\hline [Pi] $(\mathrm{mmol} / \mathrm{kg}$ wet wt) & $2.7 \pm 0.4$ & $7.2 \pm 1.1^{*}$ & $11.6 \pm 1.7^{*}$ & $13.5 \pm 1.1^{*}$ & $15.0 \pm 0.7^{*}$ & $15.1 \pm 0.9^{*}$ & $2.7 \pm 0.4$ \\
\hline [ADP] $(\mathrm{mmol} / \mathrm{kg}$ wet $\mathrm{wt})$ & $4.7 \pm 0.5$ & $16.2 \pm 3.0^{*}$ & $28.3 \pm 6.8^{*}$ & $19.8 \pm 4.1^{*}$ & $14.6 \pm 3.0^{*}$ & $13.0 \pm 2.3^{*}$ & $4.7 \pm 0.5$ \\
\hline $\mathrm{pH}$ & $7.0 \pm 0.1$ & $7.0 \pm 0.1$ & $6.9 \pm 0.1$ & $6.6 \pm 0.1^{*}$ & $6.4 \pm 0.1^{*}$ & $6.4 \pm 0.1^{*}$ & $7.0 \pm 0.1$ \\
\hline $\operatorname{MSNA}(U)^{\ddagger}$ & $348 \pm 50$ & $329 \pm 50$ & $402 \pm 94$ & $592 \pm 82^{*}$ & $773 \pm 104^{*}$ & $814 \pm 83^{*}$ & $444 \pm 36$ \\
\hline $\operatorname{MAP}(m m H g)$ & $87 \pm 2$ & $92 \pm 2 *$ & $96 \pm 2 *$ & $108 \pm 2 *$ & $112 \pm 4^{*}$ & $109 \pm 4^{*}$ & $88 \pm 2$ \\
\hline HR (beats/min) & $65 \pm 4$ & $70 \pm 4^{*}$ & $73 \pm 4^{*}$ & $84 \pm 5^{*}$ & $90 \pm 6^{*}$ & $66 \pm 4$ & $67 \pm 4$ \\
\hline
\end{tabular}

Entries are mean $\pm \mathrm{SE}$ for seven subjects. Abbreviations as in Table $\mathrm{I} .{ }^{*} P<0.05$ vs. control values. ${ }^{\ddagger}$ MSNA given in units (burst/min $X$ mean burst amplitude).

was linked to decreases in muscle cell $\mathrm{pH}$ rather than to increases in either muscle tension or central command. During the third and fourth minutes of rhythmic exercise, MSNA rose steadily as $\mathrm{pH}$ decreased progressively even though developed tension (i.e., dynamometer force) remained constant. During postexercise forearm vascular occlusion, handgrip-induced decreases in intracellular forearm $\mathrm{pH}$ and increases in peroneal MSNA were maintained even though muscular relaxation eliminated central command. This maintained sympathetic response might possibly have occurred because forearm vascular occlusion per se stimulated glycolysis or activated mechanosensitive muscle afferents (suprasystolic external tissue pressure). These possibilities are unlikely because brief forearm occlusion alone, without preceding exercise, had no effect on pH or MSNA.

The relationship between intracellular $\mathrm{pH}$ and reflex sympathetic activation suggests several possible mechanisms for the chemical stimulation of the extracellular muscle afferent receptors. The simplest mechanism is that these receptors are directly activated by cellular efflux of hydrogen ions. Alternatively, the receptors may be stimulated by some other metabolites whose cellular transport is $\mathrm{pH}$-dependent. Furthermore, because $\mathrm{pH}$ determinations by ${ }^{31} \mathrm{P}-\mathrm{NMR}$ are thought to reflect primarily the intracellular rather than the extracellular compartment, we cannot exclude the possibility that the receptors are stimulated by metabolites such as bradykinin (16), potassium (17), or arachidonic acid (18), whose accumulation accompanies augmented glycolytic activity.

Our findings are consistent with several recent reports. In anesthetized animals, infusion of lactic acid, but not of lactate ions at neutral $\mathrm{pH}$, into the arterial supply of resting muscle activated unmyelinated muscle afferents (18) and caused reflex increases in arterial pressure and heart rate (19). In conscious dogs, the arterial pressure response to progressive muscle ischemia during exercise was highly correlated with venous effluent pH (20). Taken together, these findings in experimental animals and our findings in humans suggest that glycolytic production of lactic acid may be important in the stimulation of the muscle afferents that reflexly increase sympathetic outflow.

Unlike pH, exercise-induced changes in [ADP], $\left[\mathrm{P}_{\mathrm{i}}\right]$, and $[\mathrm{PCr}] /\left[\mathrm{P}_{\mathrm{i}}\right]$ were dissociated both in time course and magnitude from changes in sympathetic traffic. This was an unexpected finding because previous observations had suggested that chemosensitive muscle afferents might be activated by some of the same metabolites that stimulate mitochondrial respiration (21). For example, during large muscle dynamic exercise, heart rate and cardiac output consistently increase in direct proportion to increases in total body oxygen consumption $(22,23)$. Furthermore, uncoupling of mitochondrial respiration from phosphorylation with dinitrophenol in anesthetized dogs has produced increases in heart rate and cardiac output of comparable magnitude to the increases that normally accompany the stimulation of oxygen consumption produced by actual muscle contraction (24). Although we have not excluded the possibility that muscle afferent regulation of muscle sympathetic outflow is influenced by ADP, $P_{i}$, or other metabolites that stimulate mitochondrial respiration, no simple relationship is suggested by the data. Furthermore, our ability to dissociate heart rate from $[A D P],\left[P_{i}\right]$, and $[\mathrm{PCr}] /\left[\mathrm{P}_{\mathrm{i}}\right]$ during postexercise forearm ischemia suggests that heart rate is not closely linked to mitochondrial respiration state during this form of exercise.

In summary, this study documents a strong relationship between muscle cell $\mathrm{pH}$ and sympathetic outflow during forearm exercise in humans. These observations strengthen the concept that the reflex sympathetic response to contraction is coupled to specific biochemical events in the exercising muscles and suggest that glycolysis may be important in the activation of this contraction-induced sympathetic reflex. The findings may have important clinical implications regarding the reflex autonomic control of the circulation during exercise in patients with alterations in skeletal muscle glycolysis due to cardiac failure, peripheral arteriosclerosis, or inborn errors of muscle metabolism.

\section{Acknowledgments}

The authors thank Jere H. Mitchell, M.D. for his continued advice and support. We also thank Ms. Lilia Urias for superb research assistance and Ms. Janet Wright and Ms. Pamela Kay Maass for secretarial assistance.

This research was supported by National Institutes of Health grants HL-06296 (Drs. Victor and Nunnally), RR-02584 (Dr. Nunnally), HL-07360 (Drs. Bertocci and Pryor); Clinical Investigator Award HL-01886 (Dr. Victor); and the American Heart Association, Texas Affiliate and the Ruby D. Hexter Estate (Dr. Victor). Drs. Bertocci and Pryor were supported by National Heart, Lung and Blood Institute Training Grant HL-07360. 


\section{References}

1. Eldridge, F. L., D. E. Millhorn, and T. G. Waldrop. 1981. Exercise hyperpnea and locomotion: parallel activation from the hypothalamus. Science (Wash. DC). 211:844-846.

2. Alam, M., and F. M. Smirk. 1937. Observations in man upon a blood pressure raising reflex arising from the voluntary muscles. $J$. Physiol. (Lond.). 89:372-383.

3. McCloskey, D. I., and J. H. Mitchell. 1972. Reflex cardiovascular and respiratory responses originating in exercising muscle. J. Physiol. (Lond.). 224:173-186.

4. Volkmann, A. W. 1841. Die Bewegungen des Athmens und Schluckens, mit besonderer Berücksichtigung neurologischer Streitragen. In Archiv für Anatomie, Physiologie und wissenschaftliche Medizin. G Eichler, Berlin. 332-360.

5. Kaufman, M. P., K. J. Rybicki, T. G. Waldrop, and G. A. Ordway. 1984. Effect of ischemia on responses of group III and IV afferents to contraction. J. Appl. Physiol. 57:644-650.

6. Wyss, C. R., J. L. Ardell, A. M. Scher, and L. B. Rowell. 1983. Cardiovascular responses to graded reductions in hindlimb perfusion in exercising dogs. Am. J. Physiol. 245:H481-H486.

7. Moon, R. B., and J. H. Richards. 1973. Determination of intracellular pH by ${ }^{31} \mathrm{P}$ nuclear magnetic resonance. J. Biol. Chem. 284:7276-7278.

8. Taylor, D. J., P. J. Bore, P. Styles, D. G. Gadian, and G. K. Radda. 1983. Bioenergetics of intact human muscle by a ${ }^{31} \mathrm{P}$ nuclear magnetic resonance study. Mol. Biol. Med. 1:77-94.

9. Taylor, D. J., P. Styles, P. M. Matthews, D. A. Arnold, D. G. Gadian, P. Bore, and G. K. Radda. 1986. Energetics of human muscle: exercise-induced ATP depletion. Magn. Reson. Med. 3:44-54.

10. Chance, B., and G. R. Williams. 1955. Respiratory enzymes in oxidative phosphorylation. I. Kinetics of oxygen utilization. J. Biol. Chem. 217:383-393.

11. Lardy, H. A., and H. Wellman. 1952. Oxidative phosphorylations: role of inorganic phosphate and acceptor systems in control of metabolic rates. J. Biol. Chem. 195:215-225.

12. Chance, B., S. Eleff, J. S. Leigh, Jr., D. Sokolow, and A. Sapega. 1981. Mitochondrial regulation of phosphocreatine/inorganic phosphate ratios in exercising human muscle: A gated ${ }^{31} \mathrm{P}$ NMR study. Proc. Natl. Acad. Sci. USA. 78:6714-6718.
13. Vallbo, A. B., K.-E. Hagbarth, H. E. Torebjörk, and B. G. Wallin. 1979. Somatosensory proprioceptive, and sympathetic activity in human peripheral nerves. Physiol. Rev. 59:919-957.

14. Mark, A. L., R. G. Victor, C. Nerhed, and B. G. Wallin. 1985. Microneurographic studies of the mechanisms of sympathetic nerve responses to static exercise in humans. Circ. Res. 57:461-469.

15. Victor, R. G., D. R. Seals, and A. L. Mark. 1987. Differential control of heart rate and sympathetic nerve activity during dynamic exercise. J. Clin. Invest. 79:508-516.

16. Stebbins, C. L., and J. C. Longhurst. 1986. Bradykinin in reflex cardiovascular responses to static muscular contraction. J. Appl. Physiol. 61:271-279.

17. Wildenthal, K., D. S. Mierzwiak, N. S. Skinner, Jr., and J. H. Mitchell. 1968. Potassium-induced cardiovascular and ventilatory reflexes from the dog hindlimb. Am. J. Physiol. 215:542-548.

18. Rotto, D. M., and M. P. Kaufmann. 1988. Effects of metabolic products of muscle contraction on discharge of group III and IV muscle afferents. J. Appl. Physiol. 64:2306-2313.

19. Thimm, F., M. Carvalho, M. Babka, E. Meier zu Verl. 1984. Reflex increases in heart-rate induced by perfusing the hind leg of the rat with solutions containing lactic acid. Pflügers Arch. Eur. J. Physiol. 400:286-293.

20. Sheriff, D. D., C. R. Wyss, L. B. Rowell, and A. M. Scher. 1987. Does inadequate oxygen delivery trigger pressor response to muscle hypoperfusion during exercise? Am. J. Physiol. 253:H1 199-H1 207.

21. Liang, C.-S., and W. B. Hood, Jr. 1976. Afferent neural pathway in the regulation of cardiopulmonary responses to tissue hypermetabolism. Circ. Res. 38:209-214.

22. Åstrand, P.-O., T. E. Cuddy, B. Saltin, and J. Stenberg. 1964. Cardiac output during submaximal and maximal work. J. Appl. Physiol. 19:268-274.

23. Barger, A. C., V. Richards, J. Metcalfe, and B. Günther. 1956. Regulation of the circulation during exercise. Cardiac output (direct Fick) and metabolic adjustments in the normal dog. Am. J. Physiol. 184:613-623.

24. Liang, C.-S., and W. B. Hood, Jr. 1973. Comparison of cardiac output responses to 2,4-dinitrophenol-induced hypermetabolism and muscular work. J. Clin. Invest. 52:2283-2292. 